\title{
Hey Look at Me: The Effect of Giving Circles on Giving ${ }^{\diamond}$
}

\author{
${ }^{*}$ Dean Karlan and ${ }^{+}$Margaret A. McConnell
}

\author{
May 15, 2013
}

\begin{abstract}
Theories abound for why individuals give to charity. We conduct a randomized field experiment with a Yale service club and find that the promise of public recognition increases giving. Some may claim that they give when offered public recognition in order to motivate others to give too, rather than for the more obvious expected private gain from increasing one's social standing. To tease apart these two theories, we also conduct a laboratory experiment with undergraduates. Our evidence is not consistent with individuals giving primarily because of a desire to influence the gifts of others. We conclude that social image motivations are a central determinant of giving when gifts are publicly recognized.
\end{abstract}

Keywords: prosocial behavior, experiments, voluntary contributions, social image

JEL: D64, C90, L30

\footnotetext{
* Department of Economics, Yale University, National Bureau of Economic Research, Innovations for Poverty Action and the M.I.T. Jameel Poverty Action Lab: dean.karlan@yale.edu

+ Harvard School of Public Health, Innovations for Poverty Action and the M.I.T. Jameel Poverty Action Lab: mmcconne@hsph.harvard.edu We would like to thank the staff of Dwight Hall and Jacob Marcus for their help in implementing the randomized field experiment. We are grateful to Lint Barrage and the staff of the Decision Lab at Yale for assistance running lab experiments at Yale. Thanks to Brooke Berman, Ya-Ting Chuang and Angela Vargas for research assistance. We thank Sera Linardi for input on experimental design. We thank Ragan Petrie, Sara Solnick, Li Hao, Danila Serra, Paula Cordero Salas, Jane Zhang and audiences at ESA and CSWEP for helpful feedback.
} 


\section{Introduction}

Models from both economics and psychology suggest that individuals may be particularly concerned with the visibility of their actions to others in the context of pro-social behavior. Benabou and Tirole (2006) develop a model of pro-social behavior that focuses on social image as one of the principal motivations for giving publicly to charity. Charitable organizations understand individuals' desire to receive recognition for their generosity, and provide a plethora of opportunities for lasting social recognition such as printing donors' names in newsletters and renaming town civic centers in order to recognize large gifts.

Organizations commonly provide recognition in discreet giving circles. These giving circles provide social image benefits, by conferring a distinct status to contributors for giving at different high levels. Veblen (1899) suggested that social comparisons are an important driver of individual behavior. Likewise, public giving may be an example of conspicuous consumption as suggested by Heffetz (2011). Limited empirical work exists on public recognition of donors, with the exception of important empirical evidence from Harbaugh (1998), which analyzes observational data from a university that uses giving circles, and argues that individuals give strategically in order to enter a higher circle. From the laboratory, Linardi and McConnell (2011) find that individuals volunteer more when their volunteering is observable to others. Ariely, Bracha and Meier (2009) present evidence that individuals exert more effort in generating gifts for charity when their work is publicly observable. In addition, Lacetera and Macis (2010) show that individuals are more likely to donate blood when they receive publicly announced awards.

However, the anticipation of a public announcement of one's gift may generate greater donations for two reasons: by providing donors with social image benefits, as just discussed, but also by offering donors the opportunity to encourage others to give in the future. In simpler terms, the reason is akin to donors saying "Hey look at me, aren't I generous!" and the second is akin to donors saying "Hey look at me, follow my lead."

The second reason, giving publicly in order to encourage others to give, could occur through one of at least two mechanisms, either because the gift provides a quality signal to others or because the gift influences the gifts of others through mimicry or social influence. For the quality mechanism, Vesterlund (2003) provides a theoretical model in which individuals may give more to a charity if contributions are publicly announced and the charity's quality is 
unknown. Indeed, evidence from a field experiment conducted by Rondeau and List (2008) suggests that challenge gifts given at the start of fundraising campaigns are highly motivating. Similarly, Potters, Sefton and Vesterlund (2005) find larger donations in public goods games when gifts are announced sequentially and the quality of public goods is unknown. The second mechanism is through peer persuasion (DeMarzo et al 2003), where a donor effectively persuades others to mimic their contribution. If there is conformity in behavior around giving (Bernheim 1994), individuals might correctly assume that their gift would have some influence even if all agents were perfectly informed about the quality of the charity. Here we provide evidence from a randomized field experiment to test whether promising social recognition for a donation increases the willingness to donate. We then differentiate between the two broad motivations, simple social image rewards versus the aspiration to influence others' choices, in a controlled laboratory setting. We do not test separately the quality signal versus persuasion or conformity mechanism.

We conducted a field experiment with a telephone fundraising campaign targeting 4,168 prior donors to Dwight Hall, a service organization at Yale University that solicits support from alumni independently of Yale University's core alumni fundraising appeals. Prior to the experiment, Dwight Hall had instituted a giving circles framework whereby individuals who give above specific thresholds are listed in a public newsletter in three circles. We randomly assigned some individuals to a treatment where they were told about the practice of publishing names in the newsletters. Within that group, we randomized which level of giving was mentioned. We find that mentioning the newsletter increases the probability of giving, and this result is both economically and statistically significant. The sub-treatment on the amount of the threshold did not lead to statistically significant differential giving amounts. Individuals appeared to respond to the potential for public recognition, but not in a strategic way.

Teasing apart the two reasons explained above (social status vs desire to motivate others to give) is difficult in a field experiment. We considered an approach in the field, such as finding an event (rather than a cause or specific charity) for which to fundraise and then randomizing whether a promise of public recognition is announced before the event (to stimulate more giving) or after the event (to appeal only to one's desire for social recognition). However, since most events are repeated, or at a minimum part of a larger cause, we were not convinced such a design would satisfactorily tease apart these theories. We thus decided to turn to a lab experiment, where the separation between rounds of giving is more distinct and more plausible. The laboratory is not meant to perfectly mimic the field but instead allows us to 
compare two different types of public giving motives in a controlled setting.

In a laboratory setting with undergraduates, we set up a three-round experiment with individuals making decisions to keep $\$ 5$ or donate all or part of it to the Global Fund to Fight Malaria, AIDS and Tuberculosis. Individuals' decisions in the second round are written on the board for the entire room to see. In an influence treatment, everyone is told that the names will be written on the board after a second period and before a third period while in a social image treatment, everyone is told that the names will be written on the board after the third period, at the end of the experiment. If subjects are partly motivated by a desire to influence others, we would expect to see higher gift amounts in the influence treatment. However we find no statistically significant difference between giving in the two treatments. The evidence thus suggests that the additional opportunity to influence others does not motivate individuals to increase their gifts. This evidence points toward social image rather than a desire to influence others as the more significant motivation for charitable giving.

The paper proceeds as follows. Section II describes the experimental design and results of the field experiment. Section III describes the experimental design and results of the lab experiment. Section IV concludes.

\section{$2 \quad$ Field Experiment}

\section{Experimental Design}

We conducted a natural field experiment in collaboration with Dwight Hall, a service club at Yale University, as part of their annual phone-a-thon campaign. The campaign took place over the course of eight months from October 2007 to May 2008 and was staffed by a rotating group of volunteers from student groups on campus. The sample frame consisted of all $(4,168)$ alumni in Dwight Hall's prior-donor database who had a valid phone number and had not already made a donation between January 2007 and October 2007. Volunteers made calls one to two times a week in the evening. Since volunteers had to read different scripts for different potential donors they were not blinded to the experimental design. Calls were made by a rotating crew of volunteers from across Yale's student groups. As many as three attempts were made to reach potential donors. The call began by informing donors that the purpose of the annual campaign is to raise funds to support the many Dwight Hall groups. This 
was followed by a request for a gift, at which point we applied treatments with differing information regarding the recognition that donors would receive in the newsletter. We do not have a measure of effort by the callers, and thus one could argue, and we have no data to refute, that the caller worked harder on the giving circle script than the other.

Dwight Hall regularly published the names of donors who give above $\$ 100$ dollars sorted in three distinct circles in the annual newsletter sent to alumni. The "Friends" circle included any gift above $\$ 100$ and below $\$ 500$, the "Benefactor" circle included gifts of at least $\$ 500$ but less than $\$ 1000$, and the "Patrons" circle included any gift of $\$ 1000$ or more. These giving circles had never been mentioned in any prior annual phone-a-thon. Our primary treatment mentioned in the phone call the potential for publicly disclosing gifts in a newsletter to alumni. In principle, any and all subjects could have already known that donors above certain thresholds get this recognition. Thus, the intervention can be thought of as providing a combination of increased salience and potentially new information.

Potential donors were randomly assigned into the following four treatment scripts with equal probability:

- Control: We are hoping you will continue your support to Dwight Hall with a gift of $\$ 100$.

- 100 circle: We are hoping you will continue your support to Dwight Hall with a gift of $\$ 100$. With a donation of at least $\$ 100$, you will become a member of our Friend donor circle. Friends will be listed by name in the Dwight Hall Fall 2008 newsletter.

- 500 circle: We are hoping you will continue your support to Dwight Hall with a gift of $\$ 100$. With a donation of at least $\$ 500$, you will become a member of our Benefactor donor circle. Benefactors will be listed by name in the Dwight Hall Fall 2008 newsletter.

- 100 circle and 500 circle: We are hoping you will continue your support to Dwight Hall with a gift of $\$ 100$. With a donation of at least $\$ 100$, you will become a member of our Friends donor circle. With a donation of at least $\$ 500$, you will become a member of our Benefactor donor circle. Both Friends and Benefactors will be listed by name in the Dwight Hall Fall 2008 newsletter.

The random assignments were implemented by the researchers using a Stata script after being provided a list by Dwight Hall of those to be called. The researchers then gave the list to Dwight Hall staff, and callers then looked up each callee prior to calling to know 


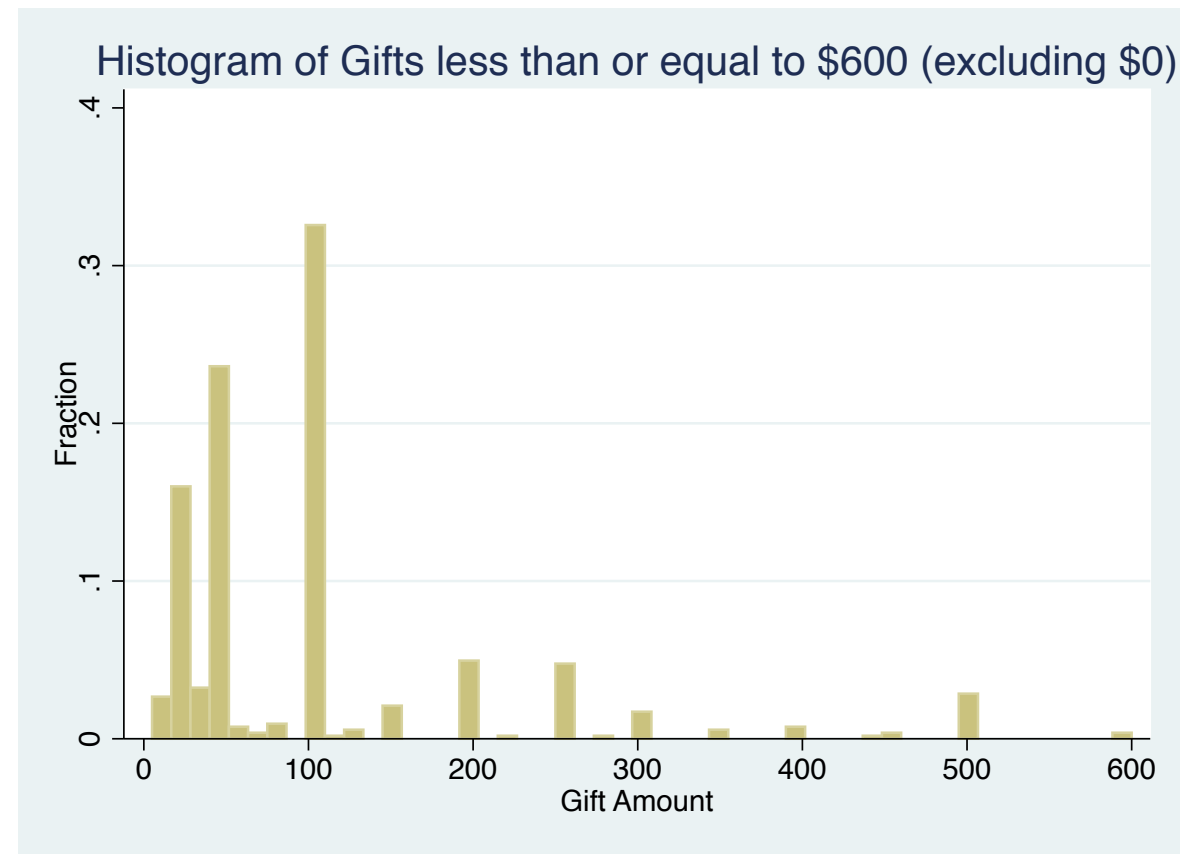

Figure 1

which treatment to use in their phone call. The randomization was not stratified, as prior donor behavior was not available at the start of the experiment and the sample size was deemed sufficiently large. Table 1 includes summary statistics and a check of the orthogonality between assignment to treatment and observable characteristics such as prior giving of the individuals.

\section{Results}

Of the 4,168 individuals targeted for the campaign, $13 \%$ made a donation. The average gift size for those who gave was $\$ 186$. Figure 1 presents the distribution of gifts greater than $\$ 0$ and less than $\$ 600$. The majority of individuals give in round number amounts (such as $\$ 50$, $\$ 100, \$ 150$, etc), which limits our power to detect small but strategic change in gift amounts designed to cross a giving circle threshold.

In Table 2 Panel A, we consider the impacts of the treatment on five outcome variables: the probability of any gift, the probability of a gift below the threshold of being published in the newsletter, the probability of a gift large enough to publish in the Friends circle, the probability of a gift large enough to publish in the Benefactor circle and the log of the gift 
amount (after adding one, to avoid dropping those who did not give). We find a $2.7 \%$ increase in the probability of making any gift across all three treatments that mention the possibility of publishing names in a newsletter. Mentioning the newsletter increases the possibility of a gift of at least $\$ 100$ by $1.8 \%$ and the probability of a gift of at least $\$ 500$ by $0.5 \%$. We see a positive but not significant increase in the probability of a donor making a gift below the level that would qualify for inclusion in the newsletter. Average gift size increases by $14 \%$. We see slightly larger effects from the treatments which mention the $\$ 500$ gift needed to enter the Benefactor circle, but we cannot detect statistically significant differences across the three treatment cells that mention the newsletter.

We also consider the potential for a heterogeneous response to treatment depending on prior gift size in Table 2 Panel B. Overall, we see that the response to treatment is increasing in the average amount of prior gifts. ${ }^{1}$ This would seem to be a natural consequence of the mechanics of the treatment, since the social reward is only relevant to those who give above $\$ 100$. The fact that we see a positive response to the opportunity to be published in a newsletter but a relatively low incidence of gifts near strategic circle cut-off points (as observed by Harbaugh 1998) suggests that the charitable organization may not have chosen the optimal circle levels to maximize contributions. Alternatively, it may be that individuals respond to the potential for public recognition instinctively (by increasing the tendency to give) but not strategically (in order to receive greater prestige) in this setting.

Andreoni and Petrie (2004) suggest that the opportunity to give anonymously may be an effective mechanism for increasing gifts in public. Consistent with evidence from Glazer and Konrad (1996), we see a very low rate of anonymous giving in our study, with 24 out of 4,168 individuals choosing to make anonymous gifts ( $0.58 \%$ of the total). A test of equality of the proportion making an anonymous gift between the control group and the treated group where individuals were informed about the newsletter yields a z-statistic of 0.652 . The results of our analysis are unchanged regardless of whether we include anonymous gifts.

\footnotetext{
${ }^{1}$ Because relatively few prior donors give $\$ 500$ donors we do not have power to detect heterogeneous treatment effects by the circle occupied in the previous campaign.
} 


\section{Lab Experiment}

The results from our field experiment leave open the important question of whether donors give more when they know their gift could be public because of concern for their social image or because they believe they could influence others to give more. We turn to the controlled environment of a laboratory experiment to answer this question. Our laboratory design incorporates elements of the field (individuals made contributions to a real charity) with control over the timing of when gifts are revealed and the opportunity for future donations.

\section{Experimental Design}

We conducted a series of experiments with Yale University's Behavioral Lab. The first wave of sessions was conducted in and around April 2010, and the second wave was conducted in September and October of 2010. The experimental protocols and forms can be found in Appendix 1.

The lab experiment consisted of two treatments: an Image treatment and a Influence treatment. Across both treatments, all subjects began by making a decision to divide $\$ 5$ between themselves and the Global Fund to Fight AIDS, Malaria and Tuberculosis (GF). This first round establishes a baseline of subjects' behaviors without the opportunity for public recognition. The rest of the experiment consisted of two additional rounds where subjects decided how to divide $\$ 5$ between themselves and GF. The treatments were designed to hold constant

all aspects of the choice to give in the second round except for the opportunity to influence the choice of others in the third and final round, described in greater detail below.

\section{Influence Treatment}

Decision \#2: Subjects were instructed that they would make two more rounds of decisions and were told that the amount they gave and their name would be written on the board following their decision in round 2 and prior to their decision in round 3 .

The experimenter wrote each subject's full name and donation decision \#2 on the black board in the room.

Subjects made decision \#3. 


\section{Image Treatment}

Decision \#2: Subjects were told that they would make two more rounds of decisions and that the amount they gave and their name would be written on the board following their decision in Round 3.

Subjects made decision \#3.

The experimenter wrote each subject's full name and donation decision \#2 on the black board in the room.

After making all three decisions and after all names were written on the board, each subject was then given two survey forms (the "Big Five Survey" and the "Lab Survey" in Appendix 1) which measured personality traits associated with leadership skills and information about whether subjects knew others participating in the experiment. After the subjects completed the surveys, the experimenter paid the subjects and subjects were debriefed about the objective of the experiment (see the "Debrief form" in Appendix 1). ${ }^{2}$

The opportunities for image seeking are identical across the two treatments. However, in the "influence" treatment, individuals have an additional motive: their gifts could influence the gifts of others in the third round. ${ }^{3}$ Therefore our experiment allows us to measure the strength of the influence motivation. Since the nature of the publicity differs across lab and field settings, we do not expect to directly compare the level of gifts in each of the two experiments.

\section{Results}

We conducted 19 sessions of the experiment with a total of 94 subjects. Summary statistics are presented in Table 1. One potential concern about the laboratory experiment is that because subjects did not choose the charity, they did not feel altruistically toward the charity and may have had less motivation to influence others. However we do see a positive willingness to give, with average gifts of $\$ 1.76$ in the first round of giving where gifts are not publicized so they is no social recognition motivation for giving. Unfortunately, our laboratory sessions were not

\footnotetext{
${ }^{2}$ This step was required by Yale's IRB.

${ }^{3}$ It could be that subjects in the influence treatment decide to strategically give less in order to prevent free-riding by other subjects. However this contradicts evidence reported that average contributions increase from round 1 to round 2 across all treatments.
} 
balanced on donations in round 1. For this reason, we run all estimations with and without controls for round 1 behavior.

Consistent with what we see in the field, the average gifts are higher in Round 2 when they will be published for the group to see. ${ }^{4}$ In Table 3, we present analysis of the relative importance of the influence and social image motivations. Panel A focuses on how gifts change when subjects know their gifts will be publicized prior to a round where others will give again. When we don't account for round 1 behavior, subjects in the influence treatment gave $\$ 0.72$ more in the second round than those in the image treatment which is an economically but not significantly significant increase in giving. However, once we control for the decision made in round one, the influence treatment increases giving by only $\$ 0.13$, which is not statistically significant. Because our sample size is relatively small, we cannot precisely estimate a zero impact of the influence treatment. We also consider whether the treatment effects changes when subjects have friends in the room (defined as people they had conversed with in the past). Both with and without controlling for first round behavior, subjects give slightly more in the influence treatment when they have friends in the room, though the effect again is not statistically significant. In order to account for potential session level effects, we also estimate treatment effects by considering the average treatment effects on average gifts at the session level. When we consider only the average difference in average gifts in round 2, there is a significant difference between the influence and image treatments, with an increase of $\$ 0.88$ or a $56 \%$ increase. However, these differences likely represent imbalance in the lab experiment treatments. Controlling for first round behavior, groups give $\$ 0.05$ less in the second round in the influence treatment and the difference is not statistically significant.

In Panel B, we consider whether gifts in the final (unpublicized) round change when gifts are publicly announced in the second round. We find that gifts in the third round increase when gifts in the second round are publicized. However, as above, this effect is no longer significant once we control for first round behavior. We test whether the influence treatment has a larger impact when there are friends in the room. We find a small and not statistically significant increase in the effectiveness of the influence treatment when there are friends in the room. We also measure whether the average of session level average gifts changes when gifts are publicized in prior rounds. We see an increase in round three giving due to the influence treatment but

\footnotetext{
${ }^{4}$ Note that we cannot causally determine whether gifts increase because of increased social recognition. Our experiment is not determined to measure the impact of social recognition but instead to distinguish between influence and social image motivations.
} 
the difference is not statistically significant once we control for first round giving. ${ }^{5}$ Finally, we consider how the influence treatment affects the variance in behavior after gifts are publicized, considering the hypothesis that gifts converge to a norm when publicly revealed. Instead, we find that publicizing gifts creates greater noise. The standard deviation of round 3 gifts increases significantly when gifts are revealed in round 2 in the influence condition. This increase in variance persists once we control for the variance in round 1. We conclude that providing information from peer giving is a stimulus, albeit in different directions for different individuals, and is thus akin in this setting to increasing the noise and thus the variance of giving.

Since treatments were assigned at the cluster level, individual actions may be correlated within experimental sessions. Cameron et al (2008) illustrate that with a small number of clusters (19 experimental sessions in our case), cluster standard errors can be biased downward. We do not include conventional cluster standard errors for this reason. We use the procedure described by Cameron et al (2008) to conduct a "wild bootstrap." Using the wild bootstrap methodology, the t-statistic for the null hypothesis that the difference between influence and image treatments is zero, is $t=0.44$ with a p-value well beyond conventional levels of significance. We conclude that we see no statistically significant distinction between the two treatments.

Overall, we do not find that the influence treatment significantly increases gifts or that it causes future gifts to increase. Though our confidence intervals and a slight imbalance in first round behavior do not allow us to rule out the possibility of some positive effects of the influence treatment in the individual analysis, once we control for first round behavior and consider session level effects we see no meaningful differences in giving as a result of the influence treatment. We conclude that the influence motivation does not seem to be a central or consistent driver of behavior in this experiment.

It could be that individuals in our laboratory experiment do not increase their gifts when they have the opportunity to signal to others because they rationally conclude that their gifts will have no influence on others' behavior. Evidence from Potter, Sefton and Vesterlund (2007) suggests that sequentially giving does not increase donations in public goods game when the quality of the public good is commonly known. However, in the case of the Global Fund, there is no reason to believe that all individuals will have perfect information about the quality of

\footnotetext{
${ }^{5}$ We see no statistically significant differences between the response to the influence treatment by individuals' level of giving compared to the group average in round 2 .
} 
this charity. Furthermore, even with perfect information, subjects might hope to influence others to give more by giving more if there is some tendency toward conformity as suggested by Bernheim (1994).

\section{Conclusion}

We present evidence from a combination of a natural field experiment and a laboratory experiment that supports the hypothesis that public recognition is an important factor influencing the decision to donate to charity. Furthermore, we find that the tendency to give in public cannot be entirely explained by a desire to influence the gifts of others. Methodologically, we demonstrate how field and laboratory experiments can complement each other. In this instance, the field experiment demonstrated an effect which had two theoretically plausible explanations, and the laboratory experiment then followed with the purpose of separating out the two theories.

Giving circles are related to but different than challenge or matching grants, and the empirical literature on the latter is much longer. The giving circles we study differ from challenge grants in important ways. Publicized giving circles offer simultaneous visibility as opposed to sequential gifts which are a characteristic of leader or challenge grants. Furthermore, unlike challenge grants where wealthy and connected individuals send a signal with their gift, giving circles offer social visibility among peers. Evidence from Shang and Croson (2009) suggests that individuals are influenced to give more when informed of others' gifts, but only when the gift size of others is comparable to their own. Giving circles also may provide an opportunity to signal effectively to peers and influence their gifts in future charitable contribution campaigns. Individuals may also hope to influence or persuade others to give even if they do not have new information about quality (Demarzo et al 2003).

Our work is related to evidence from Andreoni and Petrie (2004) and Savikhin and Sheremeta (2010), which illustrates how removing anonymity influences willingness to give in a public goods game. However, our lab experiment differs from public goods games by offering very diffuse and limited private benefits. Individuals receive no monetary benefit from the amount of total gifts given to the Global Fund over the course of the experiment. Our experiment therefore abstracts away from concerns about fairness, punishment and free-riding which are important social motivators in public goods games conducted in the lab (Fehr and Gachter 
2000) but may not be a primary determinant of charitable contributions in the field. Furthermore, our work provides an opportunity to identify whether the motive for giving in public can be primary linked to a desire for prestige or a hope that a public gift will influence others. In prior work that identifies donors, gifts have the potential to provide direct social benefits as well as to influence the gifts of others.

Substantively, the evidence here suggests that the promise of social recognition by charities to donors works not because individuals see it as an opportunity to influence others, but rather to increase one's social status. Individuals may give either because they want to be seen by others as altruistic, to avoid being seen as someone who is ungenerous (Savakhin and Sheremeta 2011), or simply to be part of a club of people that do give. Either way, it implies private gains, not altruism, as the driving force. The influence explanation may be popularly given since it provides a rationalization for otherwise selfish behavior. However, in the laboratory experiment we find no evidence that individuals increase their gifts when gifts have the opportunity to influence others' contributions. Naturally, this could be a consequence of the laboratory setting, or the fact that donors did not get to choose their own charity, and in other settings individuals might be more responsive to the opportunity to influence others' gifts. Further work to understand what those circumstances are would be beneficial, both for understanding more about the science of giving, and also practically for learning how to spread good information about effective charities. Regardless, these experiments provide clear justification for the common fundraising practice of publicly recognizing donors, and also provide clear evidence that social status, and not pure altruism, is an important driver of charitable giving.

However, we would not necessarily interpret our results to mean that organizations should shut down a potential opportunity to signal to others. Although in this laboratory context we did not find that prior gifts by others increased the amount of future gifts, this could certainly be the case in other settings, with other donors (e.g., with donors with reputations for having more accurate information on charity quality).

Individuals may be able to maintain a sense of their identity as modest and altruistic if their motives blur between influence and prestige. The billionaire's pledge, a pledge for billionaires to donate half of their wealth to charity, is motivated as a way to "encourage others to give." 6 Benabou and Tirole's (2006) model of social image and pro-social behavior illustrates that in

\begin{tabular}{ccccccc}
\hline${ }^{6}$ Peter Singer, Giving & Pledge & Media & Release, & December & 8, & $2010:$ \\
http://givingpledge.org/Content/media/PressRelease_12_8.pdf & & &
\end{tabular}


equilibria, gift giving could decrease with public recognition if the recognition dampens the signal of one's altruism and if giving in public is seen as image-seeking only. The difficulty of differentiating between image-seeking and influence motives may therefore be crucial to the success of fundraising campaigns that publicly recognize donors. Lastly, there are important policy prescriptions from understanding the influence mechanism better and for distinguishing between persuasion and quality-signaling. For example, if the mechanism at work here is quality signaling, then this suggests a potential need for improved information on charity quality. 


\section{References}

[1] Andreoni, J. (1989), "Giving with Impure Altruism: Applications to Charity and Ricardian Equivalence," Journal of Political Economy, 97 (6), 1447-1458.

[2] Andreoni, J. and Petrie, R. (2004), "Public goods experiments without confidentiality: a glimpse into fund-raising," Journal of Public Economics 88(7-8), 1605-1623.

[3] Ariely, D., Bracha, A. and Meier, S. (2009), "Doing Good or Doing Well? Image Motivation and Monetary Incentives in Behaving Prosocially," American Economic Review, 99(1), 544-55.

[4] Benabou, R. and Tirole, J. (2006), "Incentives and Prosocial Behavior," American Economic Review, 96 (5), 841-877.

[5] Bernheim, D. (1994), "A Theory of Conformity," Journal of Political Economy, 102 (5), 1652-1678.

[6] DeMarzo, P., Vayanos, D. and Zwiebel, J. (2003) "Persuasion Bias, Social Influence, and Unidimensional Opinions," Quarterly Journal of Economics, 118:03, 909-968.

[7] Fehr, E., and Gachter, S. (2000), "Cooperation and Punishment in Public Goods Experiments," American Economic Review, 90, 980-994.

[8] Glazer, A., and Konrad, K. (1996), "A signaling Explanation for Charity," American Economic Review, 86, 1019-1028.

[9] Harbaugh, W. (1998), "What do donations buy?: A model of philanthropy based on prestige and warm glow," Journal of Public Economics, 67(2), 269-284.

[10] Heffetz, O. (2011), "A Test of Conspicuous Consumption: Visibility and Income Elasticities," The Review of Economics and Statistics, 93(4), 1101-1117.

[11] Linardi, S. and McConnell, M. (2011), "No Excuses for Good Behavior," Journal of Public Economics, 95(5-6): 445-454.

[12] Lacetera, N. and Macis, M. (2010), "Social image concerns and prosocial behavior: Field evidence from a nonlinear incentive scheme," Journal of Economic Behavior \&3 Organization, 76(2), 225-237. 
[13] Potters, J., Sefton, M. and Vesterlund, L. (2005), "After you-endogenous sequencing in voluntary contribution games," Journal of Public Economics, 89(8), 1399-1419.

[14] Potters, J., Sefton, M. and Vesterlund, L. (2007), "Leading-by-example and signaling in voluntary contribution games: an experimental study," Economic Theory, 33(1). 169-182.

[15] Roundeau, D. and List, J. (2008), "Matching and challenge gifts to charity: evidence from laboratory and natural field experiments," Experimental Economics, 11(3), 253-267.

[16] Savikhin, A. and Sheremeta, R. (2010), "Visibility of Contributions and Cost of Information: An Experiment on Public Goods," Working Paper University of Chicago.

[17] Shang, J. and Croson, R. (2009), "A Field Experiment in Charitable Contribution: The Impact of Social Information on the Voluntary Provision of Public Goods," Economic Journal, 119(540), 1422-1439.

[18] Soetevent, A. (2011), "Payment Choice, Image Motivation and Contributions to Charity: Evidence from a Field Experiment," American Economic Journal: Economic Policy, 3(1), 180-205.

[19] Veblen, T. (1899), The Theory of the Leisure Class, New York, NY.

[20] Vesterlund, L. (2003), "The Informational Value of Sequential Fundraising," Journal of Public Economics, 87(3-4): 627-657. 


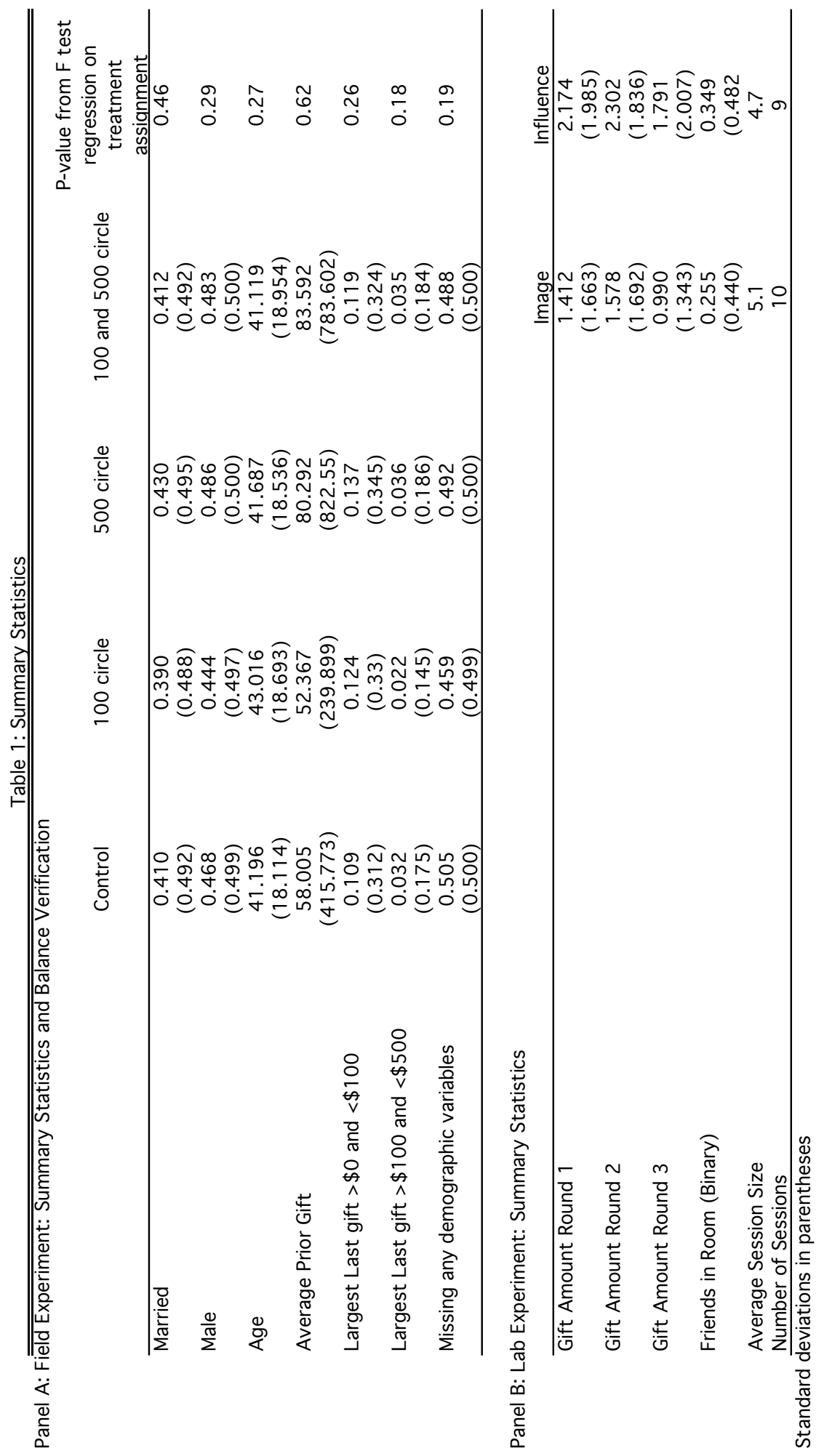




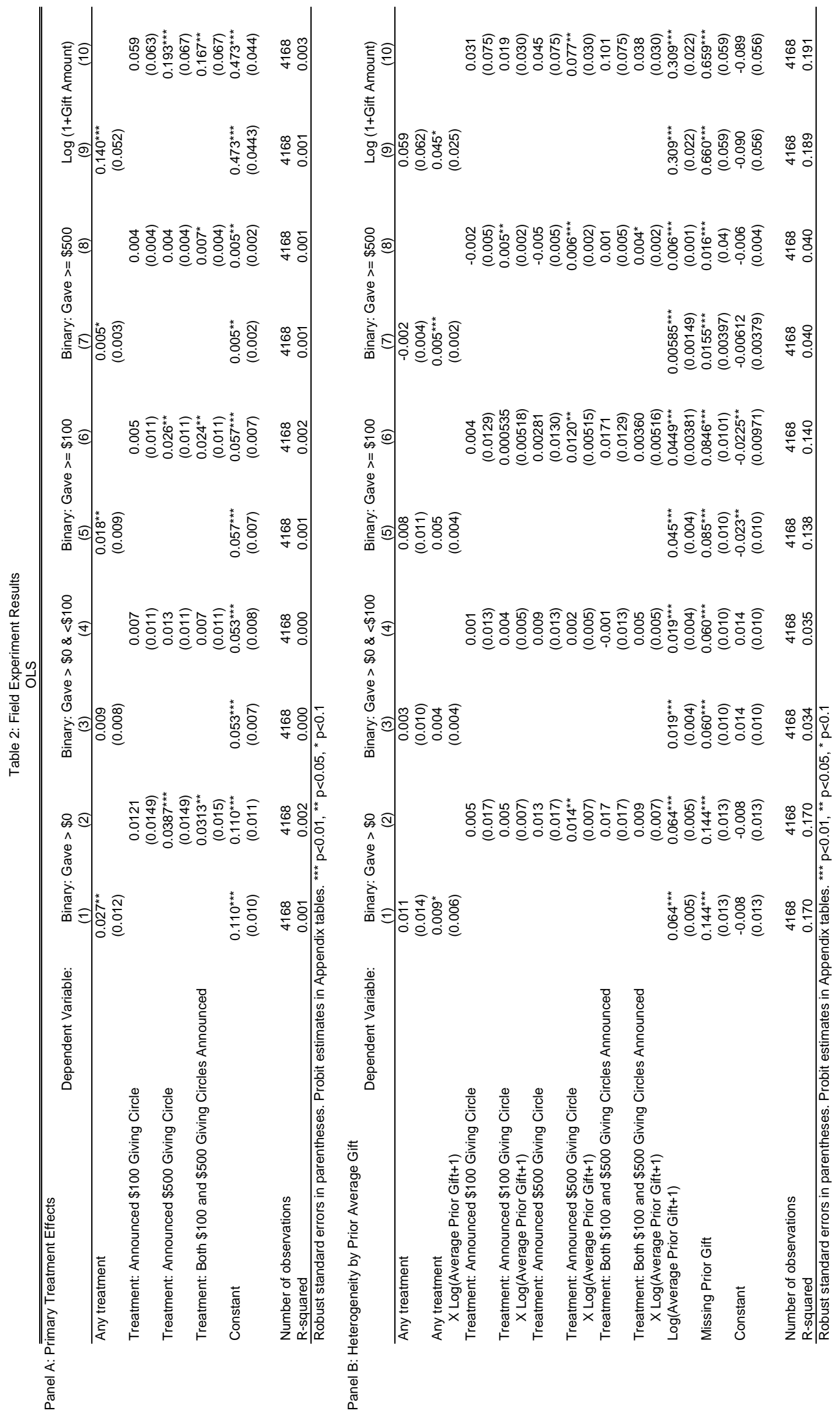




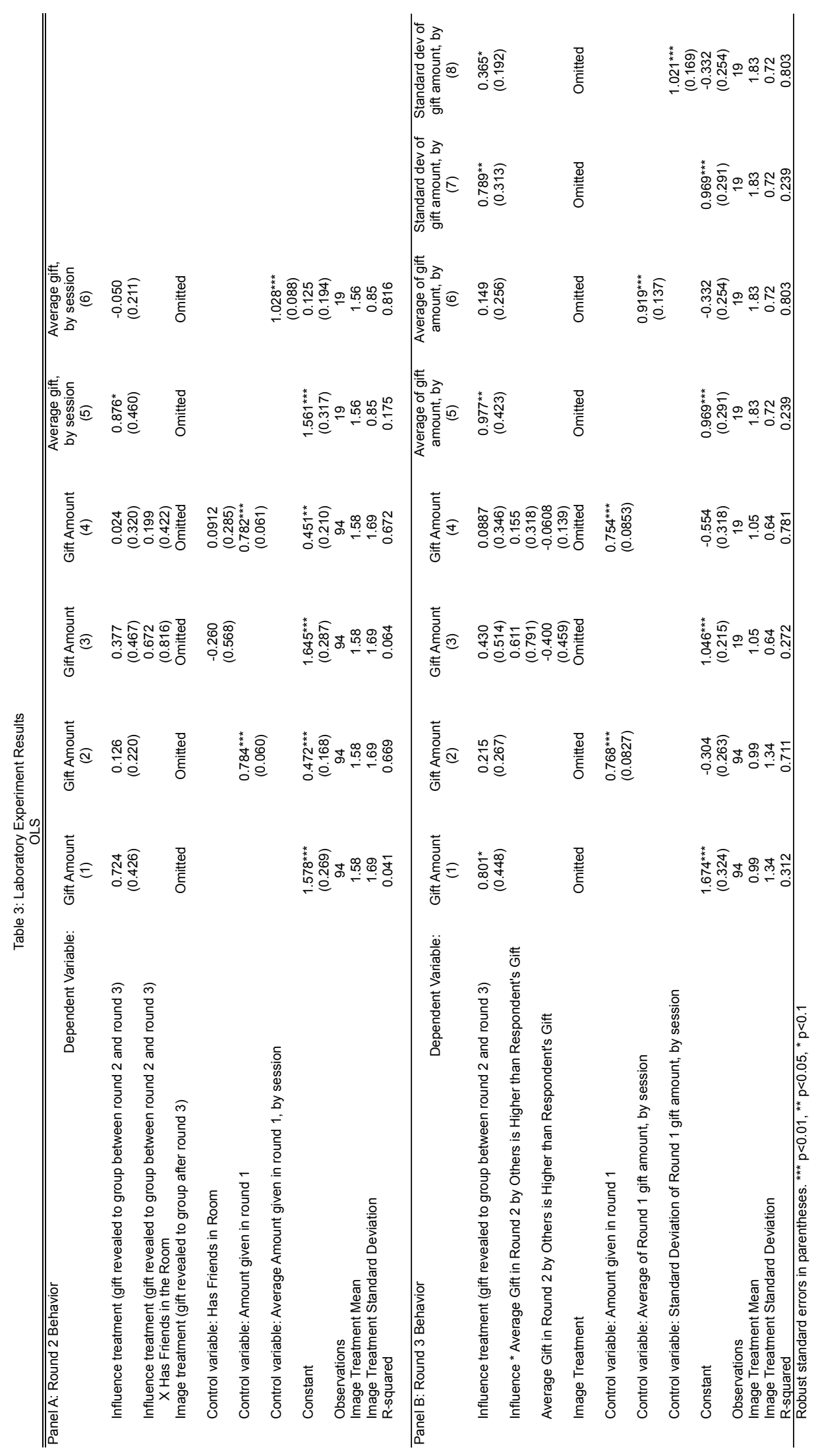




\section{Appendix1: Experimental Protocol, Instructions, Forms, Debrief and Survey}

All supporting documents are provided below. Note that the experimental protocol description below refers to the relevant document names in quotation marks.

\section{Recruitment}

Students were recruited primarily through emails sent by Yale University's Behavioral Lab manager on the Lab's listhost (see "Recruitment Email" for email example), as well as through campus flyers ("Recruitment flyer"). The recruitment informed students of available time slots for the experiment, and asked them to get in touch with an email address to schedule and confirm a time slot. The first wave of sessions was conducted in and around April 2010, and the second wave was conducted in September/October of 2010.

\section{Experimental Protocol}

When subjects arrived at the experiment, they were greeted by the experimenter. The same person served as experimenter throughout all sessions. Though assistance was provided in some sessions by other research assistants, only the experimenter spoke to the subjects during the experiment.

Upon arrival, subjects were asked to show the experimenter their Yale University student ID and were assigned a subject ID number. The subjects were then asked to sit down in the seat designated by a card to correspond to their ID number.

In their seats, subjects found an informed consent form ("Consent Form").

After all subjects registered for a session had arrived, or when five minutes had passed since the start of the official appointment time, the door was closed, the consent forms were collected, and the experiment began.

Decision \#1: First, each subject was given the "Decision \#1" sheet. The experimenter read the instructions out loud. After all subjects had entered their choices, the decision sheets were collected.

The remainder of the experiment differed depending on the treatment group.

\section{Signaling Treatment}

Decision \#2: Next, the decision \#2 sheets ("Decision \#2 - Signaling") were distributed. Once again, the experimenter read the instructions out loud, waited for subjects to write down their choices, and collected the decision sheets.

After the experimenter collected the decision sheets, she wrote each subject's full name and donation decision \#2 on the black board in the room. 
Decision \#3: Next, decision \#3 sheets (“Decision \#3") were handed out to the subjects. The experimenter read the instructions out loud, waited for the subjects to write down their choices, and collected the decision sheets.

Survey: Next, each subject was then given two survey forms (the "Big Five Survey" and the "Lab Survey"). While the subjects completed the surveys, the experimenter calculated each subject's payment, and prepared the appropriate amounts.

After all subjects had completed their surveys, the experimenter collected the survey forms. Subjects were then called out of the room in order of their subject ID number. Subjects were paid in private, initialed for the receipt of their money, and received a debrief form ("Debrief form").

\section{Image Treatment}

Decision \#2: After the decision \#1 forms were collected, decision \#2 sheets (“Decision \#2 - Image") were distributed. The experimenter read the instructions out loud, waited for the subjects to write down their choices, and collected the decision sheets.

Decision \#3: Next, decision \#3 sheets ("Decision \#3") were handed out to the subjects. The experimenter read the instructions out loud, waited for the subjects to write down their choices, and collected the decision sheets.

The experimenter then wrote each subject's full name and donation decision \#2 on the black board in the room.

Survey: Next, each subject was then given two survey forms (the "Big Five Survey" and the "Lab Survey"). While the subjects completed the surveys, the experimenter calculated each subject's payment, and prepared the appropriate amounts.

After all subjects had completed their surveys, the experimenter collected the survey forms. Subjects were then called out of the room, in order of their subject ID number. Subjects were paid in private, initialed for the receipt of their money, and received a debrief form ("Debrief form"). 


\section{Decision \#1}

Thank you for coming. During this experiment, please do not talk to other participants, if you have any questions please raise your hand and an experimenter will come to you to answer it in private. Today you will be participating in an experiment in decision making. All the decisions you make today will be real. Any money you earn today will be given to you in cash at the end of the experiment. Any money you donate to a charity will be sent directly to the charity by the experimenters.

Decision \#1: You will be given $\$ 5$. You must decide how much of the $\$ 5$ to keep for yourself and how much you'd like to give to The Global Fund to Fight AIDS, Tuberculosis and Malaria.

Your decision: (Enter how much you will keep)

\section{Decision \#2 - Signaling}

Decision \#2: Again, you will be given $\$ 5$. You must decide how much of the $\$ 5$ to keep for yourself and how much you'd like to give to The Global Fund to Fight AIDS, Tuberculosis and Malaria. Your name and your contribution decision will be provided to the other participants after they make this same decision (decision \#2). Note that after the information is revealed to everyone, there will be a third and final decision in which you will again allocate $\$ 5$ to either yourself or the Global Fund to Fight AIDS, Tuberculosis and Malaria, but that final decision will be kept private.

Your decision: (Enter how much you will keep)

\section{Decision \#2 - Image}

Decision \#2: Again, you will be given $\$ 5$. You must decide how much of the $\$ 5$ to keep for yourself and how much you'd like to give to The Global Fund to Fight AIDS, Tuberculosis and Malaria. After all individuals have made all of their decision, your name and your contribution decision will be provided to the other participants after they finish the study. Note that there will be a third and final decision after this one in which you will again allocate $\$ 5$ to either yourself or the Global Fund to Fight AIDS, Tuberculosis and Malaria, but that final decision will be kept private.

Your decision: (Enter how much you will keep)

\section{Decision \#3}

Decision \#3: You must decide how much of the $\$ 5$ to keep for yourself and how much you'd like to give to The Global Fund to Fight AIDS, Tuberculosis and Malaria. This decision will be kept private.

Your decision: (Enter how much you will keep) 


\section{Debrief Form}

\section{Debrief Form:}

The purpose of this study is to learn why individuals give more when their gifts are publicly recognized. The experiment is designed to determine whether the informational content of one's gift as a signal to others is more important than the positive social image benefits from a public gift.

\section{Lab Survey}

Did you come with anyone to the lab today?

YES

NO

How many of the people in this room have you had a conversation with 


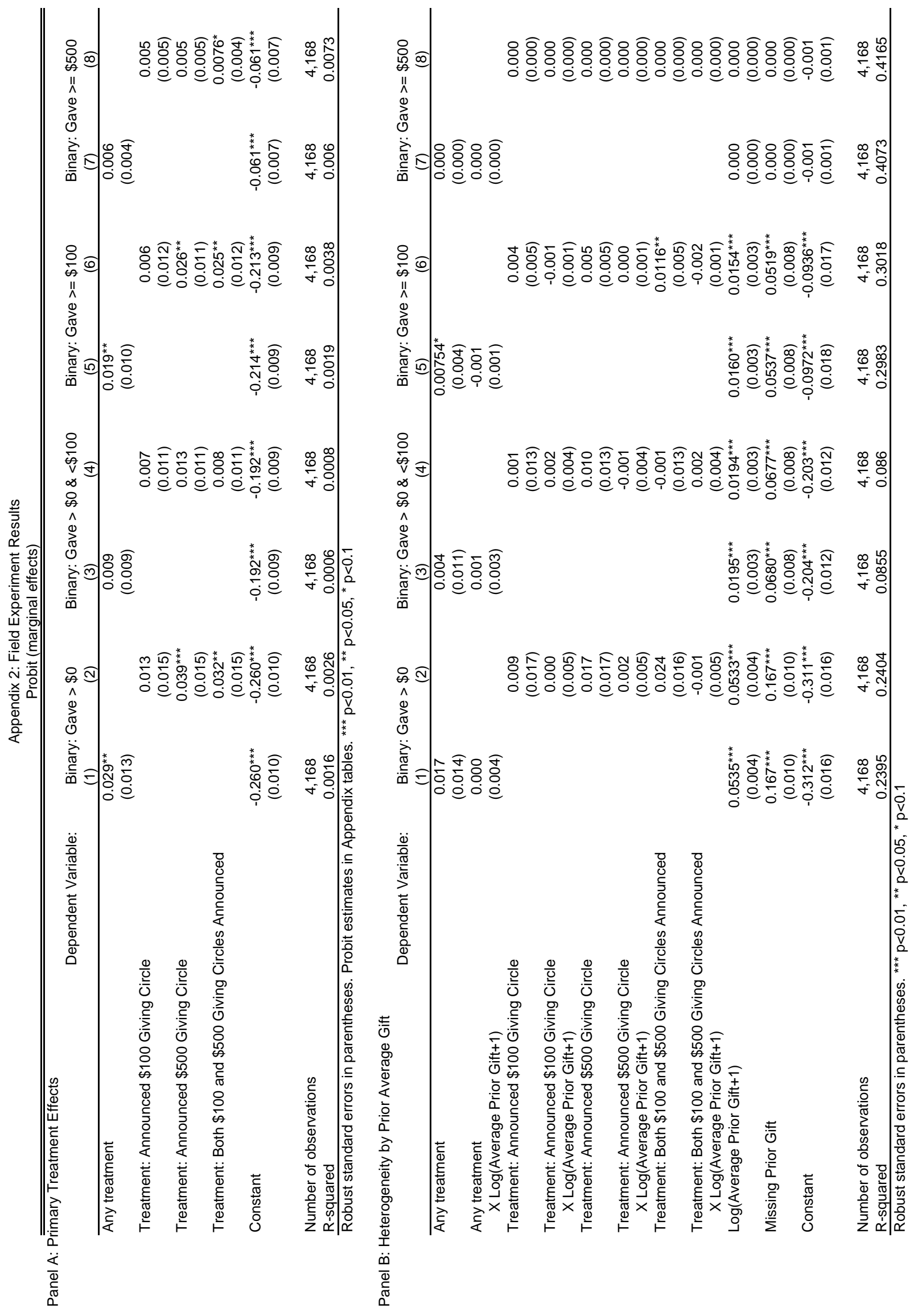

